\title{
Intestinal parasitosis and anaemia among patients in a Health Center, North Ethiopia
}

\author{
Megbaru Alemu ${ }^{*}$, Birhane Kinfe ${ }^{2}$, Desalegn Tadesse ${ }^{3}$, Wondemagegn Mulu' ${ }^{1}$,Tadesse Hailu ${ }^{1}$ \\ and Endalew Yizengaw ${ }^{1}$
}

\begin{abstract}
Objective: The aim of this cross-sectional study was to determine the magnitude of intestinal parasitosis and anaemia in a Health Center, North Ethiopia.

Results: A total of 427 outpatients were enrolled and the median age of the participants was 22 years. The prevalence of intestinal parasitosis was 143 (33.5\%). Age, place of residence and occupation were significantly associated with intestinal parasitosis. When we see parasite specific factors, significant associations were observed for source of drinking water $(P=0.02)$, age $(P<0.001)$ and family size $(P=0.003)$, respectively with Entameba histolytica, Hookworm and Giardia lamblia infections. The overall prevalence of anaemia was 35 (8.2\%). The mean haemoglobin concentration among the study participants was $12.8 \mathrm{mg} / \mathrm{dl}$. The highest prevalence of anemia was recorded for the age group of 15-19 years (29.6\%). The proportion of anemia among intestinal parasite -infected and non-infected participants was 10.7 and $7.0 \%$, respectively. Study participants infected with S. stercoralis and hookworm were more likely to develop anaemia than the non- infected ones; AOR (adjusted odds ratio) $=5.3,95 \% \mathrm{Cl}(1.01-27.4)$; $\mathrm{P}=0.028$ and $\mathrm{AOR}=11.1,95 \% \mathrm{Cl}(3.36-36.9) ; \mathrm{P}=0.000$, respectively.
\end{abstract}

Keywords: Intestinal parasite, Anaemia, Adwa, Ethiopia

\section{Introduction}

Different species of intestinal parasites are responsible for majority of human infections resulting in considerable morbidity and mortality worldwide [1]. Roughly, a quarter of the world's population is infected by one or other species of intestinal parasites [2]. Prevalence of intestinal parasitic infections varies in person, time, age and sex [3]. In Ethiopia, different studies addressed the magnitude of intestinal parasitosis among school-age children [4-12]. However, the pattern of intestinal parasitism in a population with diverse groups of people was not illustrated.

In addition to the wide-range morbidity and mortality, intestinal parasitosis (IP) is also associated with malnutrition, anaemia, impaired mental function, impaired verbal

\footnotetext{
*Correspondence: mgbeyney@gmail.com

1 Department of Microbiology, Immunology and Parasitology,

Bahir Dar University, PO Box 79, Bahir Dar, Ethiopia

Full list of author information is available at the end of the article
}

ability, physical weakness and low educational achievement in school children $[13,14]$. For instance, hookworm infection cause anaemia by increasing blood and iron loss in the intestinal tract [15]. Some other species such as Ascaris lumbricoides, Entamoeba histolytica, Trichuris trichiura, Strongyloides stercoralis and Giardia lamblia have also been found to have great effect on nutritional status due to increased metabolic rate, anorexia and diarrhoea $[15,16]$. IPs cause decreased intake or a functional increase in the body's nutrient requirement by their interference with absorptive surfaces, physical obstruction of intestinal lumen, production of proteolytic substances, and consumption of nutrients intended for the body $[14,17,18]$.

Only few studies have been conducted describing the possible contribution of intestinal parasitic infection for occurrence of anaemia in a community in Ethiopia in general and the current study area in particular. Hence, 
investigations focusing on this issue are particularly appropriate for the design of integrated control strategies aimed at reducing anaemia and IPs, including anti-parasitic treatment programs and micronutrient supplementation in a community basis. In light of this, the present study was aimed at determining the magnitude of IP and examining the relationships of haemoglobin $(\mathrm{Hb})$ concentration and anaemia with IPs among outpatients at Adwa Health Center, North Ethiopia.

\section{Main text \\ Methods \\ Study design, period and area}

A cross-sectional study was conducted from February to June, 2016 at Adwa health centre. Adwa is found in the central zone of Tigray regional state, $946.1 \mathrm{~km}$ away from Addis Ababa. It is found in the longitude and latitude of $14^{\circ} 10^{\prime} \mathrm{N} 38^{\circ} 54^{\prime} \mathrm{E}$ and an elevation of $1907 \mathrm{~m}$ above sea level. Adwa Health Center receives patients from the town and the surrounding districts.

\section{Study participants}

The study participants for this particular research work were volunteered patients 15 years and above who were requested for stool examination in Adwa Health Center during the study period. Study participants who took medication for IPs within 1 month prior to the study were excluded. The study participants were selected by a non-probability convenience sampling.

\section{Study size}

A sample size of 427 was determined using single population proportion statistical formula by the following assumptions: $95 \%$ level of confidence, $5 \%$ margin of error and $\mathrm{P}$ (proportion) of 0.5 , and non-response rate of $10 \%$.

\section{Data collection}

Questionnaire: Data on demographic characteristics of study participants and associated factors of IP were collected using structured and pre-tested questionnaire via face-to-face interview. The interview was conducted by trained nurses.

Stool examination: The patients were supplied with labeled stool containers with tight covers bearing serial numbers of the subjects. The entire stool samples were received at the spot at an organized central place.

Faecal specimens were processed by wet mount and Kato-Katz techniques. Microscopic examination was made by experienced technicians under $10 \times$ and $40 \times$ objective lenses.

Haemoglobin estimation: Five milliliter of whole blood was collected into EDTA tubes through vein puncture from study participants. The level of haemoglobin was determined using Drabkin's Cyanmethemoglobin method. Initially, the whole blood was diluted in Drabkin's solution which lyses RBCs and release $\mathrm{Hb}$ into the solution. Oxidation of ferrous ions by potassium ferricyanide to ferric ions results in the formation of methemoglobin. Methemoglobin combines with the cyanide ions (CN-) forming Cyanmethemoglobin and absorbance is measured spectrophotometrically at $540 \mathrm{~nm}$ [40].

\section{Quality control}

Questionnaires were pre-tested on a small number of adults other than the study participants. The collected data were checked daily for consistency and accuracy. Standardized procedures were strictly followed during collection of stool and blood samples and analytical processes.

\section{Statistical analysis}

Data were entered and analyzed using statistical software package (IBM Comp. released2011. IBM SPSS statistics for windows, version 20 Armonk, NY: IBM comp.). Descriptive statistics were used to describe study participants in relation to relevant variables. Chi square and logistic regression tests were employed to measure association of dependent and independent variables. Those variables with $\mathrm{P}<0.2$ in the binary logistic regression were taken to multiple regression analysis and the AOR was calculated to control potential confounders. P-values less than 0.05 were taken statistical significant.

\section{Results}

\section{Demographic characteristics}

A total of 427 study participants were enrolled in the current study. Of them, $50.1 \%$ were females. The median age of participants was 22 years. The mean family size was 3.7. Most were government employees (39.8\%) followed by farmers (36.5\%). Regarding educational status, $67.4 \%$ had completed secondary schools and $24.6 \%$ attended their tertiary educations.

Pipe-borne water was the main water source for drinking (81.5\%) followed by spring water (15.2\%). Most $(73.8 \%)$ were urban residents (Table 1$)$.

\section{Prevalence and risk factors of intestinal parasitosis}

The overall prevalence of IP was 143 (33.5\%). The prevalence of double and triple infection was 5.3 and $0.8 \%$, respectively. According to our study, the identified risk factors for intestinal parasitosis were sex, age, water source, occupation and family size. The prevalence of IP was higher in males (35.7\%) and in the age group of 15-19 (41.9\%).

Intestinal parasitosis was also higher among farmers (41\%), those who use well-dug water for drinking (50\%) 
Table 1 Prevalence of intestinal parasitosis among patients at Adwa Health, North Ethiopia 2016

\begin{tabular}{|c|c|c|c|c|}
\hline & \multicolumn{2}{|c|}{ Intestinal parasitosis } & \multirow[t]{2}{*}{ Total (\%) } & \multirow[t]{2}{*}{$\mathrm{X}^{2} ; \mathrm{P}$-value } \\
\hline & Positive N (\%) & $\begin{array}{l}\text { Negative N } \\
\text { (\%) }\end{array}$ & & \\
\hline \multicolumn{5}{|l|}{ Age (years) } \\
\hline $15-19$ & $67(41.9)$ & $93(58.1)$ & $160(37.5)$ & $11.4 ; 0.03$ \\
\hline $20-24$ & $30(27.5)$ & $79(72.5)$ & $109(25.5)$ & \\
\hline $25-29$ & $16(32.7)$ & $33(67.3)$ & $49(11.5)$ & \\
\hline $30-34$ & $10(35.7)$ & $18(64.3)$ & $28(6.5)$ & \\
\hline $35-39$ & $5(23.8)$ & $16(76.2)$ & $21(4.9)$ & \\
\hline$>=40$ & $15(25.0)$ & $45(75.0)$ & $60(14.1)$ & \\
\hline Total & $143(33.5)$ & $284(6.5)$ & $427(100)$ & \\
\hline \multicolumn{5}{|l|}{ Gender } \\
\hline Male & $76(35.7)$ & $137(64.3)$ & $213(49.9)$ & $1.76 ; 0.59$ \\
\hline Female & $67(31.3)$ & $147(68.7)$ & $214(50.1)$ & \\
\hline Total & $143(33.5)$ & $284(6.5)$ & $427(100)$ & \\
\hline \multicolumn{5}{|c|}{ Source of drinking water } \\
\hline Spring & $27(41.5)$ & $38(58.5)$ & $65(15.2)$ & $2.6 ; 0.61$ \\
\hline Pipe & $109(31.3)$ & $239(68.7)$ & $348(81.5)$ & \\
\hline Well dug & $7(50.0)$ & $7(50.0)$ & $14(3.3)$ & \\
\hline Total & $143(33.5)$ & $284(66.5)$ & $427(100)$ & \\
\hline \multicolumn{5}{|l|}{ Occupation } \\
\hline Civil servant & $49(28.8)$ & $121(71.2)$ & $170(39.8)$ & $7.8 ; 0.01$ \\
\hline Trader & $20(33.3)$ & $40(66.7)$ & $60(14.1)$ & \\
\hline Farmer & $64(41.0)$ & $92(59.0)$ & $156(36.5)$ & \\
\hline Housewife & $10(24.4)$ & 31 (75.6) & 41 (9.6) & \\
\hline Total & $143(33.5)$ & $284(66.5)$ & $427(100)$ & \\
\hline \multicolumn{5}{|l|}{ Family size } \\
\hline $2-4$ & 87 (29.8) & 205 (70.2) & $292(68.4)$ & $3.5 ; 0.29$ \\
\hline$>=5$ & $56(41.5)$ & $79(58.5)$ & $135(31.6)$ & \\
\hline Total & $143(33.5)$ & $284(66.5)$ & $427(100)$ & \\
\hline \multicolumn{5}{|l|}{ Residence } \\
\hline Urban & 78 (24.8) & $237(75.2)$ & $315(73.8)$ & $13.4 ; 0.0001$ \\
\hline Rural & 65 (58.0) & $47(42.0)$ & $112(26.2)$ & \\
\hline Total & $143(33.5)$ & $284(66.5)$ & $427(100)$ & \\
\hline
\end{tabular}

and those having relatively big family sizes (41.5\%). E. histolytica/dispar (13.6\%) followed by G. lamblia (7.7\%) and $S$. mansoni (3.3\%) were the most frequently identified parasite. E. histolytica/dispar was the most predominantly detected parasite (15.0\%) followed by hookworm $(4.2 \%)$ and $S$. stercolaris $(2.8 \%)$ in males. In females, $S$. mansoni $(4.7 \%)$ followed by $H$. nana, $(4.2 \%)$ were the most common infections (Table 2). The proportion of $E$. histolytica/dispar (20\%) was significantly higher in the age group of $15-19$ years than others $(\mathrm{P}=0.014)$. Moreover, the proportion of Hookworm infection was significantly higher in the age group of 35-39 years (19.0\%) than others $(\mathrm{P}<0.001)$ (Table 2$)$.
As shown in Table 2, the proportion of E. histolytica infection was significantly higher in males $(P=0.002)$ and in those who had dug-well as main water source for drinking than their counter parts $(P=0.02)$. Age was also significantly associated with hookworm infection $(\mathrm{P}<0.0001)$. The proportion of $G$. lamblia infection was significantly higher among households with higher family size than their counter parts $(P=0.003)$. Recurrent diarrhea was also significant indicator of Hookworm infection $(\mathrm{P}=0.013)($ Table 2$)$.

\section{Intestinal parasitosis and haemoglobin level of study participants}

The mean $\mathrm{Hb}$ concentration among the study participants was found to be $12.8 \mathrm{mg} / \mathrm{dl}$. The overall prevalence of anaemia was 35 (8.2\%). The mean haemoglobin level was $13.2 \mathrm{mg} / \mathrm{dl}$ ) and $12.4 \mathrm{mg} / \mathrm{dl}$ for males and females, respectively. The highest prevalence of anaemia was recorded for the age group of $15-19$ years (29.6\%) (Table 3$)$. The proportion of anaemia among intestinal parasite -infected and non-infected participants was 10.7 and $7.0 \%$, respectively (presented in the Additional file 1).

The mean haemoglobin level was lower for patients infected with hookworms $(11.04 \mathrm{mg} / \mathrm{dl})$ and S. stercoralis (11.4 mg/dl) $(\mathrm{P}<0.05)$.

Study participants infected with $S$. stercoralis were more likely to develop anaemia than the non- infected ones; AOR (adjusted odds ratio) $=5.3$, 95\% CI (1.0127.4); $\mathrm{P}=0.028$. Likewise, patients infected with hookworm were more likely to develop anaemia than non-infected counter parts; AOR $=11.1$, 95\% CI $(3.36-$ 36.9); $\mathrm{P}=0.000$ (Table 3).

\section{Discussion}

The prevailing prevalence of IP in the current study (33.5\%.) was lower than results reported from Jimma, Ethiopia (83\%) [6], Eastern Wollega (64.9\%) [18], Northern Gondar (79.8\%) [21], Southern Ethiopia (62.3\%) [22] and Teda Health Center (62.3\%) [23]. Moreover, higher prevalence was reported in Vietnam (88\%) [19] and Nigeria (52\%) [20]. This lower result in the current study might be due to the nature of study population in which school children were excluded.

In contrast, the present finding was higher than results from different localities of Ethiopia [2, 24, 25] and other parts of the world; Kashmir (18.02\%) [26] and Saudi Arabia $6.2 \%$ [27]. This might be attributable to differences in environmental and personal hygiene, source of households' water supply, and habit of walking bare-footed. The sensitivity of stool examination procedures might also play roles in the difference of IP prevalence.

The prevalence of amoebiasis (13.6\%) in the present study was higher than studies from Jimma (5.6\%) [6], 
Table 2 Distribution of intestinal parasites among outpatients at Adwa Health center, North Ethiopia, 2016

\begin{tabular}{|c|c|c|c|c|c|c|c|c|}
\hline \multirow[t]{2}{*}{ Variable } & \multicolumn{8}{|c|}{ Type of parasite } \\
\hline & $\begin{array}{l}E h \\
\mathrm{~N}(\%)\end{array}$ & $\begin{array}{l}\text { GI } \\
\text { N (\%) }\end{array}$ & $\begin{array}{l}S m \\
\mathrm{~N}(\%)\end{array}$ & $\begin{array}{l}\mathrm{Hw} \\
\mathrm{N}(\%)\end{array}$ & $\begin{array}{l}\text { Ss } \\
\mathrm{N}(\%)\end{array}$ & $\begin{array}{l}H n \\
\mathrm{~N}(\%)\end{array}$ & $\begin{array}{l}E v \\
\mathrm{~N}(\%)\end{array}$ & $\begin{array}{l}\text { Tsp. } \\
\text { N (\%) }\end{array}$ \\
\hline \multicolumn{9}{|l|}{ Age in years } \\
\hline $15-19$ & $32(20.0)$ & $16(10.0)$ & $9(5.6)$ & $3(1.9)$ & - & $6(3.8)$ & $2(1.2)$ & - \\
\hline $20-24$ & $7(6.4)$ & $8(7.3)$ & $3(2.8)$ & $1(0.9)$ & $3(2.8)$ & $4(3.7)$ & - & - \\
\hline $25-29$ & $3(6.1)$ & $5(10.2)$ & $1(2.0)$ & $2(4.1)$ & $2(4.1)$ & $1(2.0)$ & - & - \\
\hline $30-34$ & $4(14.3)$ & $1(3.6)$ & $1(3.6)$ & $2(7.1)$ & $1(3.6)$ & $1(3.6)$ & - & 1 (3.6) \\
\hline $35-39$ & $3(14.3)$ & $1(4.8)$ & - & $4(19.0)$ & $2(9.5)$ & - & - & - \\
\hline$>=40$ & $9(15.0)$ & $2(3.3)$ & - & $1(1.7)$ & - & - & - & $1(1.7)$ \\
\hline Total & $58(13.6)$ & $33(7.7)$ & $14(3.3)$ & $13(3.0)$ & $8(1.9)$ & $13(3.0)$ & $2(0.5)$ & $2(0.5)$ \\
\hline P-value & 0.014 & 0.53 & 0.32 & $<0.001$ & 0.27 & 0.65 & 0.65 & 0.1 \\
\hline \multicolumn{9}{|l|}{ Gender } \\
\hline Male & $32(15.0)$ & $18(8.5)$ & $4(1.9)$ & $9(4.2)$ & $6(2.8)$ & $4(1.9)$ & - & $2(0.9)$ \\
\hline Female & $26(12.1)$ & $15(7.0)$ & $10(4.7)$ & $4(1.9)$ & $2(0.9)$ & $9(4.2)$ & $2(0.9)$ & - \\
\hline Total & $58(13.6)$ & $33(7.7)$ & $14(3.3)$ & $13(3.0)$ & $8(1.9)$ & $13(3.0)$ & $2(0.5)$ & $2(0.5)$ \\
\hline P-value & 0.47 & 0.87 & 0.59 & 0.16 & 0.15 & 0.25 & 0.16 & 0.16 \\
\hline \multicolumn{9}{|l|}{ Occupation } \\
\hline Civil servant & $17(10.0)$ & $14(8.2)$ & $2(1.2)$ & $3(1.8)$ & $1(0.6)$ & $3(1.8)$ & & $2(1.2)$ \\
\hline Trader & $2(20.0)$ & - & $1(10.0)$ & $1(10.0)$ & $1(10.0)$ & $1(10.0)$ & & \\
\hline Farmer & $34(21.8)$ & $15(9.6)$ & $5(3.2)$ & $7(4.5)$ & $5(3.2)$ & $4(2.6)$ & $1(0.6)$ & \\
\hline Housewife & $5(5.5)$ & $4(4.4)$ & $7(6.6)$ & $2(2.2)$ & $1(1.1)$ & $5(5.5)$ & $1(1.1)$ & \\
\hline Total & $58(13.6)$ & $33(7.7)$ & $14(3.3)$ & $13(3.0)$ & $8(1.9)$ & $13(3.0)$ & & $2(0.5)$ \\
\hline P-value & 0.002 & 0.38 & 0.19 & 0.23 & 0.39 & 0.14 & 0.63 & 0.39 \\
\hline \multicolumn{9}{|l|}{ Family size } \\
\hline $2-4$ & $39(13.4)$ & $15(5.1)$ & $10(3.4)$ & $1(3.4)$ & $7(2.4)$ & $6(2.1)$ & $1(0.3)$ & $1(0.3)$ \\
\hline$>=5$ & $19(14.1)$ & $18(13.3)$ & $4(3.0)$ & $3(2.2)$ & $1(0.7)$ & $6(4.4)$ & $1(0.7)$ & $1(0.7)$ \\
\hline Total & $58(13.6)$ & $33(7.7)$ & $14(3.3)$ & $13(3.0)$ & $8(1.9)$ & $13(3.0)$ & $2(0.5)$ & $2(0.5)$ \\
\hline P-value & 0.99 & 0.003 & 0.80 & 0.50 & 0.24 & 0.17 & 0.56 & 0.56 \\
\hline \multicolumn{9}{|c|}{ Source of drinking water } \\
\hline Pipe & $45(12.9)$ & $23(6.6)$ & $10(2.9)$ & $8(2.3)$ & $6(1.7)$ & $7(2.0)$ & $2(0.6)$ & $2(0.6)$ \\
\hline Spring & $10(15.4)$ & $8(12.3)$ & $3(4.6)$ & $4(6.2)$ & $2(3.1)$ & $4(6.2)$ & - & - \\
\hline Dug-well & $3(21.4)$ & $2(14.3)$ & $1(7.1)$ & $1(7.1)$ & - & $1(7.1)$ & - & - \\
\hline Total & $58(13.6)$ & $33(7.7)$ & $14(3.3)$ & $13(3.0)$ & $8(1.9)$ & $13(3.0)$ & $2(0.5)$ & $2(0.5)$ \\
\hline P-value & 0.02 & 0.19 & 0.55 & 0.26 & 0.66 & 0.11 & 0.80 & 0.80 \\
\hline \multicolumn{9}{|c|}{ Recurrent diarrhea } \\
\hline Yes & $3(10.0)$ & $2(6.7)$ & $2(6.7)$ & $4(13.3)$ & - & $3(10.0)$ & - & - \\
\hline No & $55(13.9)$ & $31(7.8)$ & $12(3.0)$ & $9(2.3)$ & $8(2.0)$ & $10(2.5)$ & $2(0.5)$ & $2(0.5)$ \\
\hline Total & $58(13.6)$ & $33(7.7)$ & $14(3.3)$ & $13(3.0)$ & $8(1.9)$ & $13(3.0)$ & $2(0.5)$ & $2(0.5)$ \\
\hline P-value & 0.26 & 0.82 & 0.30 & 0.001 & 0.43 & 0.19 & 070 & 070 \\
\hline
\end{tabular}

Eh, E. histolytica; Ss, S. Stercolaris

Gl, G. lamblia; Ev, E. vermicularis

Sm, S. mansoni Hn, H. nana

HW, hookworms; Tsp., taenia Spp

Gondar (10.3\%) [21], Saudi Arabia (4.7\%) [27], Malaysia (0.4\%) [28], Italy (4.1\%) [29] and Myanmar (6.2\%) [30]. The relatively higher prevalence of $E$. histolytica/dispar infection in this study might be due to poor access to safe drinking water supplies which is supported by our study that majority of the study participants used dung-well and spring water sources. Over diagnosis of E. histolytica is also expected from the current study since molecular based diagnostics were not used to differentiate $E$. histolytica from E. dispar. 
Table 3 Distribution of intestinal parasite species and anaemia at Adwa Health Center, North Ethiopia 2016

\begin{tabular}{|c|c|c|c|c|c|c|}
\hline Parasite species & $\begin{array}{l}\text { Mean (Std) Hb level } \\
(\mathrm{mg} / \mathrm{dl})\end{array}$ & $\begin{array}{l}\text { Non-anemic } \\
(n=392)(\%)\end{array}$ & $\begin{array}{l}\text { Anemic } \\
(n=35)(\%)\end{array}$ & P-value & AOR & $95 \% \mathrm{Cl}$ \\
\hline Entameba histolytica & $12.94 \pm 0.09$ & $58(14.8)$ & 0 & NA & NA & NA \\
\hline Giardia lamblia & $12.62 \pm 0.02$ & $29(7.25)$ & $4(11.4)$ & 0.15 & 2.22 & $0.71-6.9$ \\
\hline Schistosoma mansoni & $12.62 \pm 0.06$ & $13(3.25)$ & $2(5.7)$ & 0.89 & 1.14 & $0.14-9.1$ \\
\hline Enterobius vermicularis & $13.50 \pm 0.01$ & $2(0.5)$ & 0 & NA & NA & NA \\
\hline Hymenolepis nana & $12.45 \pm 0.08$ & $2(0.5)$ & 0 & NA & NA & NA \\
\hline Strongyloides stercolaris & $11.39 \pm 0.08$ & $6(1.5)$ & $3(8.6)$ & 0.028 & 5.3 & $1.01-27.4$ \\
\hline Hookworms & $11.04 \pm 0.02$ & $8(2.0)$ & $6(17.1)$ & 0.000 & 11.1 & $3.36-36.9$ \\
\hline Taenia species & $13.50 \pm 0.02$ & $2(0.5)$ & - & 0.71 & & \\
\hline
\end{tabular}

NA, not applicable

The higher prevalence of hookworm infection in males than females in the present study was in agreement with studies conducted in certain parts of Ethiopia [2, 9, 21] and Brazil [39]. However, higher prevalence of hookworm infection in females was reported in Eastern Ethiopia [7], South Ethiopia [10] and Nepal [31]. The higher prevalence of hookworm in men in our study might be due to the fact that agrarian men are more frequently engaged in agricultural activities where shoe wearing is not convenient. In the present study, peak hookworm infection was recorded in participants of age 35-39 years. This result was in line with reports from Northwest Ethiopia [23], Southern Ethiopia [22], Uganda [15] and Nigeria [20,32,33]. Persistence of hookworms with age might be attributed to ignorance of foot wear among the adult agrarian males [20].

The significantly higher prevalence of $E$. histolytica infection among participants that used non-piped water supplies in the present study was consistent with reports from Eastern Wellega, Ethiopia [18]. This might be an indication for the incomplete separation of human waste with water sources that are used for drinking in the area. Our study also revealed that giardiasis was significantly higher among those with larger family sizes (> $5 \mathrm{mem}-$ bers). Consistent findings were reported from Rural Malaysia [40] and Brazil [41, 42]. This might be due to occurrence of person-to-person transmissions through direct faecal-oral contact among family members with infected children.

Occupation was also found to be related to a risk of IP in our study. The prevalence of IP was significantly higher among farmers $(41 \%)$. It was in agreement with findings from Ethiopia [42, 43] and Nigeria [44, 43]. This may be explained by the fact that farmers encounter constant contact with contaminated soil and water. Farmers also indiscriminately eat with unwashed hands after work.

In the present study the mean haemoglobin threshold was significantly lower in IP-infected than non-infected individuals $(\mathrm{P}=0.002)$. Moreover, the proportion of anaemia was also higher among outpatients who harbored IPs. These were in agreement with several studies elsewhere [19, 34-37] in which intestinal parasites were strongly associated with development of anaemia.

In this study IP due to hookworm and S. stercolaris infections were significantly associated with anaemia. This conforms to other studies conducted in Mozambique [33], Uganda [15], Bangladesh [37], Nigeria [33], Cameroon [35], Vietnam [19] and Kenya [38]. This might be because Hookworm species ((Ancylostoma duodenale and Necator americanus) cause significant blood losses through feeding and cause a daily loss into the small intestine of $0.14-0.26 \mathrm{ml}$ and $0.02-0.07 \mathrm{ml} /$ worm, respectively) and oozing of the blood at attachment site [44].

\section{Conclusion}

Co-existence of IP infections and anaemia is major public health significance among adolescents and adults in the study area. E. histolytica was significantly prevalent in the younger group (15-19 years) while hookworm infection persisted with age. Higher overall anaemia was observed for IP-infected patients.

\section{Limitations of the study}

This study didn't address the dietary and other factors that might contribute for occurrence of anaemia in the study participants.

\section{Additional file}

Additional file 1. Questionnaire and laboratory data registration form. The questionnaire was intended to collect demographic data of study participants and factors associated with intestinal parasitosis. It includes sex, age, place of residence, occupation, family size and source of drinking water among others. The laboratory data registration form on the other hand was used to record results of stool examination and haemoglobin level. 


\section{Abbreviations}

Hb: haemoglobin; EDTA: ethylenediamine tetraacetic acid; IP: intestinal parasitosis.

\section{Authors' contributions}

MA designed the study and wrote manuscript; BK participated in the design of the study, data collection and revision of the manuscript; DT participated in data analysis and revision of the manuscript, WM analyzed data and wrote the manuscript, TH participated in data analysis and write-up, EY participated in manuscript write-up. All authors read and approved the final manuscript.

\section{Author details}

${ }^{1}$ Department of Microbiology, Immunology and Parasitology, Bahir Dar University, PO Box 79, Bahir Dar, Ethiopia. ${ }^{2}$ Adwa Health Center, Tigray, Ethiopia.

${ }^{3}$ Department of Medical Parasitology and Vector Biology, Mekelle University, Mekelle, Ethiopia.

\section{Acknowledgements}

We are thankful to laboratory personnel and clinicians at Adwa HC and study participants for their contribution of this research work.

\section{Competing interests}

The authors declare that they have no competing interests.

\section{Availability of data and materials}

Data was collected and analyzed based on the stated methods and materials and the findings were generated accordingly. The manuscript incorporated all the data and there are no Additional files. The original data supporting this finding will be available at any time upon request.

\section{Consent for publication}

Individual data such as images and videos did not accompany this particular manuscript and hence consent for publication is not applicable.

\section{Ethics approval and consent to participate}

Ethical approval was sought from Mekelle University, College of Health Sciences institutional review board (IRB) and was granted accordingly with the reference number (ERC055/2016). Written consents were collected from the study participants. Parents of children of under 18 years old were informed of their children's participation and gave informed written consent for their children to participate. Assents were also collected from children. Participants positive for IPs and had anaemia were reported to the health center for appropriate treatments/management.

\section{Funding}

The research project was not funded by any funding organization.

\section{Publisher's Note}

Springer Nature remains neutral with regard to jurisdictional claims in published maps and institutional affiliations.

Received: 3 September 2017 Accepted: 21 November 2017

Published online: 28 November 2017

\section{References}

1. Quihui L, Valencia ME, Crompton DTE, Phillips S, Hagan P, Morales G, DiazCamacho SP. Role of the employment status and education of mothers in the prevalence of intestinal parasitic infections in Mexican rural schoolchildren. BMC Public Health. 2006:6:225.

2. Tefera Girum. Prevalence of intestinal parasitic infections among patients with diarrhea at Wonago health center, Southern Ethiopia: a retrospective study. Immunol Infect Dis. 2015;3(1):1-6.

3. Mbuh Judith $V$, Ntonifor Helen $N$, Ojong James T. The incidence, intensity and host morbidity of human parasitic protozoan infections in gastrointestinal disorder out patients in buea sub division. Cameroon. J Infect Dev Ctries. 2010:4:38-43.
4. Erko B, Teferi G, Medhin G. Reinfection of school children with Schistosomiasis mansoni in the Fincha valley western Ethiopia. Ethiop J Health Dev. 2004:11:269-73.

5. Erko B, Medhin G. Human helminthiasis in Wondo Genet, southern Ethiopia, with emphasis on geohelminthiasis. Ethiop Med J. 2003;41(4):333-44.

6. Yami Alemeshet, Mamo Yoseph, Kebede Seleshi. Prevalence and predictors of intestinal helminthiasis among school children in Jimma Zone; a cross-sectional study. Ethiop J Health Sci. 2011;21:167-74.

7. Girum T. The prevalence of intestinal helminthic infections and associated risk factors among school children in Babile town, eastern Ethiopia. Ethiop J Health Dev. 2005;19:140-7.

8. Legesse M, Erko B. Prevalence of intestinal parasite among school children in rural area close to the southeast of Lake Langano, Ethiopia. Ethiop Health Dev. 2004;18(2):116-20.

9. Mengistu $L$, Berhanu E. Prevalence of intestinal parasites among schoolchildren in a rural area close to the southeast of Lake Langano, Ethiopia. Ethiop J Health Dev. 2004;18:116-20.

10. Merid $Y$, Hegazy M, Mekete $G$, Teklemariam S. Intestinal helminthic infection among children at Lake Awassa area, South Ethiopia. Ethiop J Health Dev. 2001:15:31-7.

11. Assefa Shimelis, Erko Berhanu, Medhin Girmay, Assefa Zelalem, Shimelis Techalew. Intestinal parasitic infections in relation to HIV/AIDS status, diarrhea and CD4 T-cell count. BMC Infect Dis. 2009;9:155.

12. Nyantekyi LA, Mengstu L, Mulugeta B, Konjit T, Kebreten M, Chanda M. Intestinal parasitic infections among under-five children and maternal awareness about the infections in Shesha Kekele, Wondo Genet, southern Ethiopia. Ethiop J Health Dev. 2010:24(3):185-90.

13. El-Masry HM, et al. Prevalence, risk factors and impacts of schistosomal and intestinal parasitic infections among rural school children in Sohag Governorate. Egypt J Hosp Med. 2007;29:616-30

14. Nwaneri DU, Omuemu VO. Intestinal helminthiasis and nutritional status of children living in orphanages in Benin City, Nigeria. Niger J Clin Pract. 2013:16(2):243-8

15. Chami GF, Fenwick A, Bulte E, Kontoleon AA, Kabatereine NB, Tukahebwa EM, et al. Influence of Schistosoma mansoni and hookworm infection intensities on anaemia in Ugandan Villages. PLoS Negl Trop Dis. 2015;9(10):e0004193.

16. Mengistu Amare, Gebre-Selassie Solomon, Kassa Tesfaye. Prevalence of intestinal parasitic infections among urban dwellers in southwest Ethiopian. Ethiop J Health Dev. 2007:21:12-7.

17. Tadesse $D$, Tsehaye A. Impact of irrigation on the prevalence of intestinal parasite infections with emphasis on schistosomiasis in Hintallo-Wejerat, North Ethiopia. Ethiop J Health Sci. 2008;18(2):33-8.

18. Gebru AA, et al. Prevalence of intestinal parasites and associated risk factors at red cross clinic and Chelaleki health center, East Wollega Zone, Ethiopia. Sci J Pub Health. 2015:3(4):445-52.

19. Le HT, Brouwer ID, Verhoef H, Nguyen KC, Kok FJ. Anaemia and intestinal parasite infection in school children in rural Vietnam. Asia Pac J Clin Nutr. 2007:16(4):716-23.

20. Muhammad IM, et al. Intestinal parasitic infections among patients attending a Tertiary health institution in northeastern Nigeria. Am J Res Commun. 2014;2(6):88-96.

21. Asrat A, Tewodros D, Alemayehu W. Prevalence and risk factors of IPs among Delgi school children, northern Gonder, Ethiopia. J Parasitol Vectorbiol. 2011:3(5):75-81.

22. Wegayehu, et al. Prevalence of intestinal parasitic infections among highland and lowland dwellers in Gamo area, South Ethiopia. BMC Public Health. 2013;13:151.

23. Abate Abraraw, et al. Cross-sectional study on the prevalence of intestinal parasites and associated risk factors in Teda health centre, northwest Ethiopia. ISRN Parasitol. 2013. https://doi.org/10.5402/2013/757451.

24. Asfaw TS, Goitom L. Malnutrition and enteric parasitoses among under-five children in Aynalem village, Tigray. Ethiop J Health Dev. 2000;14:67-75

25. Girum T. The prevalence of intestinal helminthic infections and associated risk factors among school children in Babile town, eastern Ethiopia. Ethiop J Health Dev. 2005;19:140-7.

26. Malik TM, Baig ZF. Frequency and pattern of intestinal parasitic infestations in upper Neelum Valley. Pak Armed Forces Med J. 2006;4:67-73. 
27. Zaglool DAM, Khodari YAW, Gazzaz ZJ, Dhafar KO, Shaker HAS, Farook MV. Prevalence of intestinal parasites among patients of Al-Noor specialist Hospital, Makkah, Saudi Arabia. Oman Med J. 2011;26(3):182-5.

28. Jamaiah I, Rohela M. Prevalence of intestinal parasites among members of the public in Kuala Lumpur, Malaysia. Southeast Asian J Trop Med Public Health. 2005;36:68-71.

29. Peruzzi Simona, Gorrini Chiara, Piccolo Giovanna, Calderaro Adriana, Dettori Giuseppe, et al. Prevalence of intestinal parasites in the area of Parma during the year 2005. Acta Biomed. 2006;77:147-51.

30. Prasert R, Pitak W, Nipon T. Factors associated with intestinal parasites among households in Ratchaburi province, Thai-Myanmar border area. J Trop Med Parasitol. 2008;31:85-94.

31. Hotez PJ, Bundy DAP, Beegle K. Helminth infections; soil transmitted infections and schistosomiasis. The International Bank for Reconstruction and Development/the World Bank, 2006.

32. Ehiaghe AF, et al. Hemoglobin concentration of intestinal parasites infested children in Okada, Edo state, Nigeria. Open J Epidemiol. 2013:3:149-52.

33. Casmo V, Augusto G, Nala R, Sabonete A, Carvalho-Costa FA. The effect of hookworm infection and urinary schistosomiasis on blood hemoglobin concentration of schoolchildren living in northern Mozambique. Rev Inst Med Trop São Paulo. 2014;56(3):219-24.

34. Njunda, et al. Coinfection with malaria and intestinal parasites, and its association with anaemia in children in Cameroon. Infect Dis Poverty. 2015:4:43.

35. Ahmed SG, Uraka J. The impact of intestinal parasites on haematological parameters of sickle-cell anaemia patients in Nigeria. EMHJ. 2011;17(9):710-3.
36. Banu, et al. Relationships between anaemia and parasitic infections in adolescent girls of Bangladesh. Bangladesh J Zool. 2014;42(1):91-103.

37. Koukounari, et al. Relationships between anaemia and parasitic infections in Kenyan schoolchildren: a bayesian hierarchical modeling approach. Int J Parasitol. 2008;38(14-4):1663-71.

38. Santos FLN, Souza AMGC, Soares NM. Hookworm and threadworm infections and their association with hemoglobin and eosinophil concentrations in residents of Salvador Bahia, Brazil. Rev Inst Med Trop São Paulo. 2013;55(4):233-8.

39. Cheesbrough M. District laboratory practice in tropical countries. 2 nd ed. New York: Cambridge University Press; 2009.

40. Choy SH, et al. Prevalence and associated risk factors of giardia infection among Indigenous Communities in Rural Malaysia. Sci Rep. 2014;4:6909. https://doi.org/10.1038/srep06909.

41. Graças Cabral Pereira MD, Atwill ER, Barbosa AP. Prevalence and associated risk factors for Giardia lamblia infection among children hospitalized for diarrhea in Goiânia, Goiás state, Brazil. Rev Inst Med Trop São Paulo. 2007:49(3):139-45.

42. Alamir M, et al. Intestinal parasites infection and associated factors among school children in Dagi primary school, Amhara National Regional State, Ethiopia. Health. 2013;5(10):1697-701.

43. Houmsou RS, Amuta EU. Effects of environmental and socio-economic factors on the prevalence of intestinal parasites in school children in Makurdi, Benue State-Nigeria. Afr J Environ Pollut Health. 2009;7(1):1-6.

44. Gillespie SH, Pearson RD. Principles and practice of clinical Parasitology. 2nd ed. Toronto: Wiley; 2001.

\section{Submit your next manuscript to BioMed Central and we will help you at every step:}

- We accept pre-submission inquiries

- Our selector tool helps you to find the most relevant journal

- We provide round the clock customer support

- Convenient online submission

- Thorough peer review

- Inclusion in PubMed and all major indexing services

- Maximum visibility for your research

Submit your manuscript at www.biomedcentral.com/submit
O Biomed Central 